\title{
Metabolic syndrome in metabolic obese, non-obese elderly in northern Taiwan
}

\author{
Meng-Ting Tsou ${ }^{1,2,3^{*}}$ \\ ${ }^{1}$ Family Medicine, Mackay Memorial Hospital, Taipei, Chinese Taipei; ${ }^{*}$ Corresponding Author: mttsou@gmail.com \\ ${ }^{2}$ Mackay Medicine, Nursing and Management College, Taipei, Chinese Taipei \\ ${ }^{3}$ Mackay Medical College, Taipei, Chinese Taipei
}

Received 10 September 2012; revised 16 October 2012; accepted 25 October 2012

\section{ABSTRACT}

Background: The prevalence of metabolic syndrome is high in non-obese adult individuals, but less research focusing on elderly group. We aimed to assess the prevalence rates of metabolic syndrome (MetS) and its individual components in metabolic obese, non-obese elderly population in northern Taiwan (Body Mass Index [BMI] $<27 \mathrm{~kg} / \mathrm{m}^{2}$ ). Methods: A cross-sectional survey was conducted among elderly people ( $\geq 65$ ylo) who received a senior citizen health examination from March to November 2009. A total of $\mathbf{1 1 8 0}$ participants (433 men, 36.7\%; 748 women, $63.3 \%$ ) were investigated. The prevalence and odds ratios of metabolic syndrome, as defined by the modified Adult Treatment Panel III (ATP III), were analyzed in the following BMI groups: $<18.5 \mathrm{~kg} / \mathrm{m}^{2}, 18.5-24 \mathrm{~kg} / \mathrm{m}^{2}, 24-27$ $\mathrm{kg} / \mathrm{m}^{2}$, and $\geq 27 \mathrm{~kg} / \mathrm{m}^{2}$. Results: The prevalence of metabolic syndrome increased with BMI in both women and men $(P<0.001)$ in this study. A higher prevalence of MetS was found in the overweight and obesity groups and also in women with normal BMI. The mean body weight of individuals with MetS was higher than that of those without MetS across BMI groups, especially in the normal BMI group. The odds ratios for MetS were 1.06 (95\% confidence interval: 1.01 - 1.11) for women and $1.11(1.01$ - 1.21) for men with BMI $18.5-24 \mathrm{~kg} / \mathrm{m}^{2}$, and $1.09(1.02$ 1.17) for men with BMI $24-27 \mathrm{~kg} / \mathrm{m}^{2}$. Conclusions: Elderly individuals in the BMI belong to normal and overweight groups have a relatively high prevalence and increased risk of developing MetS. Therefore, physicians should perform screening examinations for MetS and its risk factors not only in obese patients but also in non-obese elderly patients to prevent Mets. This electronic document is a "live" template. The various components of your paper (title, text, heads, etc.) are already defined on the style sheet, as illustrated by the portions given in this document.

Keywords: Non-Obese; Body Mass Index; Metabolic Syndrome; Elderly

\section{INTRODUCTION}

Cardiovascular Heart Disease (CHD), cerebrovascular disease (CVA), and diabetes were the second, third, and fifth leading causes of death in men and women in Taiwan in 2011 [1]. Individuals with metabolic syndrome (MetS) are at an increased risk of developing these chronic diseases $[2,3]$ as well as a higher mortality risk from cardiovascular disease and all causes [4]. The Nutrition and Health Survey in Taiwan (1999-2000; NAHSIT-II), a national survey of non-institutionalized elderly Taiwanese ( $\geq 65$ years of age), showed that $21.5 \%$ of elderly men and $37.6 \%$ of elderly women met the criteria for MetS $[5,6]$. According to the modified National Cholesterol Education Program-Adult Treatment Panel III (NCEP-ATPIII) criteria, the prevalence of MetS in Taiwan in 2005 was estimated to be $30.2 \%$ among men and $48.9 \%$ among women [7]. These data suggest that there has been no decline in the prevalence of MetS from 1999 to 2005.

In the past, most studies on MetS emphasized the importance of obesity. In fact, although non-obese individuals often have some metabolism-associated disorders, they are often ignored in relation to obesity. Ruderman et al. [8] first proposed the term "Metabolically Obese, Normal-Weight" (MONW) to describe a specific group of individuals in 1981; in 2004, St-Onge et al. [9] proposed a new definition of metabolically obese, normalweight individuals as those who have MetS. They also noted a relatively high prevalence and an increased risk of MetS in Caucasians, African-Americans, and Hispanics with $\mathrm{BMI}$ in the normal-weight and overweight 
range. In 2008, Wildman et al. [10] reported a high prevalence of clustering of cardiometabolic abnormalities among normal-weight individuals.

In Taiwan, individuals in the normal weight and overweight BMI range have a relatively high prevalence and increased risk of MetS in general population [11]. Tsai provided a new definition of the term "Metabolically Obese, Non-Obese" (MONO), which emphasizes the importance of non-obese individuals in the present population of adult Taiwanese with metabolismassociated disorders. However, the characteristics of MONO elderly people have been less frequently discussed in previous studies [11].

The main objective of this study was to determine the prevalence rates and likelihood of developing MetS, as defined by the NCEP-ATPIII criteria, and its individual components in non-obese elderly individuals (BMI $<27$ $\left.\mathrm{kg} / \mathrm{m}^{2}\right)$ in northern Taiwan. It was suggested that MONO elderly individuals were those whose BMI was considered normal or overweight (non-obese), but who had any one of the following metabolic disorders that could be improved via caloric restriction: type 2 diabetes, hypertension, and hypertriglyceridemia.

This template, created in MS Word 2003 and saved as "Word 1997-2003 \& 6.0/95-RTF" for the PC, provides authors with most of the formatting specifications needed for preparing electronic versions of their papers. All standard paper components have been specified for three reasons: 1) ease of use when formatting individual papers, 2) automatic compliance to electronic requirements that facilitate the concurrent or later production of electronic products, and 3) conformity of style throughout a journal paper. Margins, column widths, line spacing, and type styles are built-in; examples of the type styles are provided throughout this document and are identified in italic type, within parentheses, following the example. Some components, such as multi-leveled equations, graphics, and tables are not prescribed, although the various table text styles are provided. The formatter will need to create these components, incorporating the applicable criteria that follow.

\section{METHOD}

\subsection{Study Populations}

This study targeted elderly individuals ( $\geq 65 \mathrm{Y} / \mathrm{O}$ ) who were native to Taipei City and received a physical examination from March to November of 2009 at one medical center in northern Taiwan. Data were collected using a questionnaire completed by the interviewer in a faceto-face session in order to avoid write-in errors. A total of 1799 elderly individuals received physical examinations in hospitals. After excluding 420 individuals who were unable to complete the questionnaire (for reasons such as dementia, difficulty in expression, or severe hearing impairment), a total of 1379 cases were included for data analysis. Due to incomplete data on the risk factors of MetS, 199 cases were eliminated. Thus, we received a total of 1180 complete questionnaires (recovery rate, $85.6 \%$ ).

\subsection{Definitions of Metabolic Syndrome}

The modified NCEP-ATPIII criteria were used in this study. MetS was defined as the presence of any 3 of the following 5 conditions: abdominal obesity (waist circumference, $\geq 90 \mathrm{~cm}$ for men and $\geq 80 \mathrm{~cm}$ for women), hyperglycemia (triglyceride [TG] level, $\geq 150 \mathrm{mg} / \mathrm{dl}$ or use of antitriglyceride agents), low serum high-density lipoprotein cholesterol (HDL-C) level (HDL-C level, $\leq 40 \mathrm{mg} / \mathrm{dl}$ for men and $\leq 50 \mathrm{mg} / \mathrm{dl}$ for women), hypertension (SBP, $\geq 130 \mathrm{~mm} \mathrm{Hg}$ and DBP, $\geq 85 \mathrm{mmHg}$ or use of antihypertensive agents), and hyperglycemia (fasting glucose, $\geq 100 \mathrm{mg} / \mathrm{dl}$ or use of antidiabetic agents), according to the Department of Health [12].

\subsection{Physical Examination and Laboratory Tests}

The height and weight of each participant were assessed during the physical check-up. BMI is a standard measure of obesity invariably adopted within the literature, and is calculated by dividing a person's weight in kilograms by the square of their height in meters $\left(\mathrm{kg} / \mathrm{m}^{2}\right)$ $[13,14]$. During the visit, sitting Blood Pressure (BP) and anthropometric measurements were made. After the participant had sat and rested for $5-10 \mathrm{~min}, 2 \mathrm{BP}$ readings in the right arm were taken 30 seconds apart. If the first two BP readings differed by more than $10 \mathrm{mmHg}$, a third BP measurement was made. The average of the two closest readings was calculated and used in the analysis [15]. Waist circumference was measured at the standard point with a tape measure placed parallel to the floor at the end of a relaxed expiration with the participants standing arms akimbo [16]. NaF plasma was collected for fasting glucose analysis, and serum was collected for the measurement of lipid levels. Fasting levels of total cholesterol, TG, and Fasting Plasma Glucose (FPG) were measured by an automated system (Vitros 550/750; Ortho-Clinical Diagnostics Inc., Johnson \& Johnson Company, Rochester, NY, USA). Electrophoresis was performed to measure HDL-C levels.

\subsection{Assessment of Socio-Demographic Variables and Health-Risk Behaviors}

The socio-demographic variables assessed in the survey included gender, education level, and living condition. Education level was classified into 1 of the following 5 levels: illiterate, elementary school, junior high school, 
senior high school, and college or higher; living condition was defined as single, and with family. Three types of health-influencing behaviors were assessed in this study during the interview. Questions regarding alcohol consumption, smoking tobacco, and regular exercise (3 times/week) in the previous 6 months were posed to each participant.

\subsection{Statistical Analysis}

SAS 9.0 software (SAS Inc., Cary, NC, USA) and SPSS 17.0 (SPSS Inc., Chicago, IL, USA) software were used for statistical analysis. Continuous variables were reported in terms of mean \pm Standard Deviation (SD) and categorical variables were reported in terms of number and percentage. Differences in proportions and means were assessed using a chi-square test, $t$ test, Fisher's exact test, and multiple logistic regression analysis. Statistical significance was set at $P<0.05$ and $P<0.01$.

We compared the prevalence of MetS and its indiviual components according to BMI category by using the chiare test. All elderly individuals were subdivided into 4 BMI groups $(\leq 18.5,18.5-24.0,24.0-27.0$, and $\geq 27.0$ $\left.\mathrm{kg} / \mathrm{m}^{2}\right)[13,14]$. Multiple logistic regression analysis was also used to examine the associations between BMI classification and MetS. Dummy variables were created to compute odds ratios and 95\% Confidence Interval (CI) values for these factors. The change to Body Weight (BW) was the independent factor. The odds ratios were adjusted for age, smoking status, alcohol consumption, exercise status, living condition, and educational level.

\section{RESULTS}

We enrolled a total of 1180 subjects, including 433 men $(36.7 \%)$ and 747 women $(63.3 \%)$. The mean age was $74.4 \pm 5.5$ years, and the age range was $65-101$ years. The mean BMI was $24.4 \pm 3.4 \mathrm{~kg} / \mathrm{m}^{2}$. The prevalence of tobacco use, alcohol consumption, and regular exercise were $3.6 \%, 8.9 \%$, and $89.7 \%$, respectively. Subject characteristics are presented in Table 1 For age, body height, body weight, and waist circumference, men had higher mean values than women, while women showed higher mean systolic pressure, lower HDL-C levels, and higher TG levels. About $95.1 \%$ of the men and $89.5 \%$ of the women were living with their family, while $10.5 \%$ of the women were single and living alone. Most men had higher education levels (senior high school or college) than women (elementary school and high school). There were significant differrences between the sexes.

The prevalence of MetS and its components is shown in Table 2 The prevalence of abnormal risk factors increased with BMI. Compared with men, a greater proportion of women had a large waist circumference $(P<$
0.001 ), and up to $95.8 \%$ of the women with a BMI $\geq$ $27.0 \mathrm{~kg} / \mathrm{m}^{2}$ had a large waist circumference. The prevalence of high glucose levels, high triglyceride levels, and low HDL-C levels increased with increasing BMI in both sexes $(P<0.001)$. Similarly, the prevalence of all MetS components increased with increasing BMI $(P<0.001)$.

The prevalence of MetS in the $<18.5 \mathrm{~kg} / \mathrm{m}^{2}, 18.5-24$ $\mathrm{kg} / \mathrm{m}^{2}, 24-27 \mathrm{~kg} / \mathrm{m}^{2}$, and $\geq 27 \mathrm{~kg} / \mathrm{m}^{2}$ BMI groups was $0 \%, 16.3 \%, 45 \%$, and $38.7 \%$, respectively, in men $(P<$ 0.001 ), and $1 \%, 30.7 \%, 37.6 \%$, and $30.7 \%$, respectively, in women $(P<0.001)$. The mean body weight was higher in individuals with MetS than in those without MetS, especially among members of the BMI $18.5-27 / \mathrm{m}^{2}$ group (Table 3).

With reference to BW changes, the odds ratios for Me$\mathrm{tS}$ were $1.11(95 \%$ CI $1.01-1.21)$ in the BMI 18.5 - 24 $\mathrm{kg} / \mathrm{m}^{2}$ group, and 1.09 (1.02 - 1.17) for men, after controlling for age, smoking status, alcohol consumption, exercise status, living condition, and educational level. The corresponding odds ratio in women was 1.06 (1.01 1.11) (Table 4).

\section{DISCUSSION}

This study, which collected data from a metropolitan elderly population in a medical center, showed that the prevalence of MetS in both elderly men and women (men: $25.6 \%$, women: $39.3 \%$ ) was similar to that seen in a national study conducted in 1999 to 2000 (men: $21.5 \%$, women: $37.6 \%$ ), but slightly lower than the results of a 2005 study (men: 30.2\%, women: 48.9\%) [5-7]. These results showed the high prevalence of elderly MetS in northern Taiwan.

In the study by St-Onge, the overall prevalence of MetS in the BMI 25.0 - $26.9 \mathrm{~kg} / \mathrm{m}^{2}$ group for an adult population with different ethnicities [9] was $9.6 \%-18.5 \%$ in men and $15.0 \%-22.5 \%$ in women. One Asian study reported overall prevalence values of $36.6 \%$ in men and $49.5 \%$ in women in the same BMI group, thus showing a higher prevalence than that observed in the study by St-Onge [11]. The prevalence of MetS was highly associated with BMI categories in men and women $(P<$ 0.001) [9-11]. Accessed May, 2012. Not only obese, but non-obese individuals may also have metabolism associated disorders, and the concept of the MONO individuals needs to be emphasized [11]. However, even in the Western or Asian countries, few studies have discussed the relevance of this classification in eldly individuals.

Our study showed that no male subjects and 3 female subjects $(10 \%)$ in the BMI $<18.5 \mathrm{~kg} / \mathrm{m}^{2}$ group fulfilled the MetS criteria. In the $18.5-24,24-27$, and $\geq 27$ $\mathrm{kg} / \mathrm{m}^{2}$ BMI groups, 108 (26.7\%), 160 (39.6\%), and $133(32.9 \%)$ subjects met the criteria for MetS. The prevalence of MetS was the highest in men with BMI 
Table 1. Characteristics of the subjects by gender.

\begin{tabular}{|c|c|c|c|c|}
\hline Variable (Mean \pm S.D. $)$ & Total $(\mathrm{n}=1180)$ & $\operatorname{Men}(n=433,36.7 \%)$ & Women $(\mathrm{n}=747,63.3 \%)$ & $P$ value \\
\hline Age (years) & $74.4 \pm 5.5$ & $75.4 \pm 5.3$ & $73.8 \pm 5.6$ & $<0.001^{\dagger}$ \\
\hline Body height $(\mathrm{cm})$ & $157.3 \pm 8.0$ & $163.8 \pm 5.7$ & $152.1 \pm 5.4$ & $<0.001^{\dagger}$ \\
\hline Body weight $(\mathrm{kg})$ & $60.5 \pm 10.1$ & $65.7 \pm 9.4$ & $56.4 \pm 8.7$ & $<0.001^{\dagger}$ \\
\hline $\operatorname{BMI}\left(\mathrm{kg} / \mathrm{m}^{2}\right)$ & $24.4 \pm 3.4$ & $24.5 \pm 3.2$ & $24.4 \pm 3.5$ & 0.344 \\
\hline Waist circumference $(\mathrm{cm})$ & $83.4 \pm 9.9$ & $85.3 \pm 9.4$ & $82.3 \pm 10.0$ & $<0.001^{\dagger}$ \\
\hline Systolic BP (mmHg) & $133.6 \pm 18.7$ & $131.3 \pm 18.2$ & $134.9 \pm 18.9$ & $0.002^{\dagger}$ \\
\hline Diastolic BP (mmHg) & $69.9 \pm 10.8$ & $70.5 \pm 11.0$ & $69.6 \pm 10.8$ & 0.145 \\
\hline HDL-C (mg/dl) & $56.6 \pm 15.7$ & $51.1 \pm 13.6$ & $59.7 \pm 16.0$ & $<0.001^{\dagger}$ \\
\hline Fasting BS (mg/dl) & $106.5 \pm 23.6$ & $106.9 \pm 25.0$ & $106.3 \pm 22.7$ & 0.643 \\
\hline $\mathrm{TG}(\mathrm{mg} / \mathrm{dl})$ & $119.1 \pm 65.0$ & $113.4 \pm 62.4$ & $122.4 \pm 66.2$ & $0.023^{*}$ \\
\hline Smoking (recent $1 / 2$ year) & & & & $<0.001^{\dagger}$ \\
\hline Yes & $43(3.6)$ & $39(9.0)$ & $4(0.5)$ & \\
\hline Alcohol (recent 1/2year) & & & & $<0.001^{\dagger}$ \\
\hline Yes & $105(8.9)$ & $90(20.8)$ & $15(2.0)$ & \\
\hline Exercise (recent $1 / 2$ year) & & & & $0.002^{\dagger}$ \\
\hline Yes & $1064(89.7)$ & $405(93.5)$ & $659(87.4)$ & \\
\hline Living condition & & & & $0.002^{\dagger}$ \\
\hline Single & $100(8.4)$ & $21(4.9)$ & $79(10.5)$ & \\
\hline With family & $1080(91.6)$ & $412(95.1)$ & $668(89.5)$ & \\
\hline Education level & & & & $<0.001^{\dagger}$ \\
\hline Illiterate & $66(5.6)$ & $8(1.9)$ & $58(7.7)$ & \\
\hline Elementary & $376(31.8)$ & 94 (21.6) & $282(37.7)$ & \\
\hline Junior high school & $212(18.0)$ & $54(12.5)$ & $158(21.2)$ & \\
\hline Senior high school & $298(25.3)$ & $128(29.5)$ & $170(22.9)$ & \\
\hline$\geq$ College & $228(19.3)$ & $149(34.6)$ & $79(10.4)$ & \\
\hline
\end{tabular}

Note: Student's $t$ test and Chi-square test were used, compare with men and women group. ${ }^{*}$ means $p<0.05,{ }^{\dagger}$ means $p<0.01$.

$24-27 \mathrm{~kg} / \mathrm{m}^{2}$ (50 subjects [45\%]; women: 110 subjects [37.6\%]), but a high prevalence was also found in women with BMI $18.5-24 \mathrm{~kg} / \mathrm{m}^{2}$ (90 subjects, $30.7 \%$ ). Therefore, clinicians must be alert to the possibility of metabo- lism-associated disorders even in elderly individuals who have BMI $<27 \mathrm{~kg} / \mathrm{m}^{2}$, especially in women. We proposed the term of Metabolically Obese, NonObese (MONO) elderly individuals to emphasize the presence of metabolism-associated disorders in non-obese elderly individuals.

The high prevalence of abnormal metabolic risk factors among elderly individuals with upper normal to slightly elevated BMI in this study suggests that the current recommendations for weight loss may need to be modified. Current weight-loss recommendations do not advise pa- tients with BMI $<24.0 \mathrm{~kg} / \mathrm{m}^{2}$ to lose weight, and dissuade the use of pharmaceutical agents as adjuncts to weightloss regimens for patients with BMI $<27.0 \mathrm{~kg} / \mathrm{m}^{2}$ [17]. Weight loss in individuals with $\mathrm{BMI}<27.0 \mathrm{~kg} / \mathrm{m}^{2}$ should be considered if they also have metabolic syndrome [9].

The cross-sectional nature of the study does not permit causal inferences to be made about the relationship be tween BMI and the MetS, but an increase in BMI is probably the cause of MetS. In this study, the aging population was gathered from several regions of the nor thern metropolitan area, and may not be representative of the entire elderly population. The prevalence might have been underestimated for some elderly individuals who may have gone to the medical center to receive physical examinations on their own, as these individuals might 
Table 2. The prevalence of risk factors of MetS in different BMI groups.

\begin{tabular}{|c|c|c|c|c|c|c|c|c|c|c|c|c|}
\hline \multirow{3}{*}{ Variable } & \multirow{3}{*}{ Total $(n=433)$} & \multicolumn{4}{|c|}{ Men } & \multirow{3}{*}{$P$ value } & \multirow{3}{*}{ Total $(n=747)$} & \multicolumn{4}{|c|}{ Women } & \multirow{3}{*}{$P$ value } \\
\hline & & \multicolumn{4}{|c|}{ BMI $\left(\mathrm{kg} / \mathrm{m}^{2}\right)$} & & & \multicolumn{4}{|c|}{$\operatorname{BMI}\left(\mathrm{kg} / \mathrm{m}^{2}\right)$} & \\
\hline & & $\begin{array}{l}\leq 18.5 \\
(\mathrm{n}=5)\end{array}$ & $\begin{array}{l}18.5-24 \\
(\mathrm{n}=189)\end{array}$ & $\begin{array}{c}24-27 \\
(n=163)\end{array}$ & $\begin{array}{c}\geq 27 \\
(n=76)\end{array}$ & & & $\begin{array}{c}\leq 18.5 \\
(\mathrm{n}=30)\end{array}$ & $\begin{array}{l}18.5-24 \\
(\mathrm{n}=340)\end{array}$ & $\begin{array}{c}24-27 \\
(\mathrm{n}=233)\end{array}$ & $\begin{array}{c}\geq 27 \\
(\mathrm{n}=144)\end{array}$ & \\
\hline \multicolumn{2}{|c|}{ Waist circumference } & & & & & $<0.001^{\dagger}$ & & & & & & $<0.001^{\dagger}$ \\
\hline Abnormal & $135(31.2)$ & $0(0.0)$ & $12(6.3)$ & $59(36.2)$ & $64(84.2)$ & & $445(59.6)$ & $1(3.3)$ & $126(37.1)$ & $180(77.3)$ & $138(95.8)$ & \\
\hline $\mathrm{BP}$ & & & & & & 0.072 & & & & & & $0.003^{\dagger}$ \\
\hline Abnormal & $227(52.4)$ & $2(40.0)$ & $88(46.6)$ & $89(54.6)$ & $48(63.2)$ & & $450(60.2)$ & $19(63.3)$ & $186(54.7)$ & $140(60.1)$ & $105(72.9)$ & \\
\hline HDL-C & & & & & & $0.001^{*}$ & & & & & & $0.003^{\dagger}$ \\
\hline Abnormal & $89(20.6)$ & $0(0.0)$ & $24(12.7)$ & $42(25.8)$ & $23(30.3)$ & & $210(28.1)$ & $4(13.3)$ & $81(23.8)$ & $70(30.0)$ & $55(38.2)$ & \\
\hline BS & & & & & & $<0.001^{\dagger}$ & & & & & & $<0.001^{\dagger}$ \\
\hline Abnormal & $237(54.7)$ & $0(0.0)$ & $89(47.1)$ & $98(60.1)$ & $50(65.8)$ & & $388(51.9)$ & $11(36.7)$ & $154(45.3)$ & $131(56.2)$ & $92(63.9)$ & \\
\hline TG & & & & & & $0.002^{\dagger}$ & & & & & & $0.001^{\dagger}$ \\
\hline Abnormal & $87(20.1)$ & $0(0.0)$ & $24(12.7)$ & $40(24.5)$ & $23(30.3)$ & & $171(22.9)$ & $4(13.3)$ & $57(16.8)$ & $66(28.3)$ & $44(30.6)$ & \\
\hline MetS & & & & & & $<0.001^{\dagger}$ & & & & & & $<0.001^{\dagger}$ \\
\hline Abnormal & $111(25.6)$ & $0(0.0)$ & $18(9.5)$ & $50(30.7)$ & $43(56.6)$ & & $293(39.2)$ & $3(10.0)$ & $90(26.5)$ & $110(47.2)$ & $90(62.5)$ & \\
\hline
\end{tabular}

Note: Chi-square test were used, compare with BMI groups. ${ }^{*}$ means $p<0.05,{ }^{\dagger}$ means $p<0.01$.

Table 3. Mean body weight in Mets and non-without-MetS by gender and BMI groups.

\begin{tabular}{|c|c|c|c|c|c|c|c|}
\hline Variable & $\mathrm{N}=1180$ & Total & $\begin{array}{c}\mathrm{N}=776 \\
65.8 \%\end{array}$ & Non-MetS & $\begin{array}{c}\mathrm{N}=404 \\
34.2 \%\end{array}$ & MetS & $P$ value \\
\hline & $\mathrm{n}$ & $\mathrm{BW}($ mean $\pm \mathrm{SD})$ & $\mathrm{n}$ & $\mathrm{BW}($ mean $\pm \mathrm{SD})$ & $\mathrm{n}$ & $\mathrm{BW}($ mean $\pm \mathrm{SD})$ & \\
\hline \multicolumn{8}{|l|}{ Men } \\
\hline Total & 433 & $66.0 \pm 9.6$ & 322 & $63.8 \pm 8.8$ & 111 & $72.8 \pm 8.8$ & $<0.001^{\dagger}$ \\
\hline \multicolumn{8}{|c|}{ BMI groups $\left(\mathrm{kg} / \mathrm{m}^{2}\right)$} \\
\hline $\mathrm{BMI}<18.5$ & 5 & $47.9 \pm 6.4$ & 5 & $47.9 \pm 6.4$ & 0 & & \\
\hline $18.5 \leq \mathrm{BM}<24$ & 189 & $59.1 \pm 5.8$ & 171 & $58.8 \pm 5.9$ & 18 & $62.1 \pm 3.9$ & $<0.001^{\dagger}$ \\
\hline $24 \leq \mathrm{BMI}<27$ & 163 & $68.4 \pm 5.1$ & 113 & $67.7 \pm 5.0$ & 50 & $69.9 \pm 5.0$ & $0.016^{*}$ \\
\hline $27 \leq \mathrm{BMI}$ & 76 & $76.3 \pm 7.2$ & 33 & $79.0 \pm 6.4$ & 43 & $79.6 \pm 7.9$ & 0.712 \\
\hline \multicolumn{8}{|l|}{ Women } \\
\hline Total & 747 & $56.4 \pm 8.7$ & 454 & $54.3 \pm 8.2$ & 293 & $59.6 \pm 8.5$ & $<0.001^{\dagger}$ \\
\hline \multicolumn{8}{|c|}{ BMI groups $\left(\mathrm{kg} / \mathrm{m}^{2}\right)$} \\
\hline $\mathrm{BMI}<18.5$ & 30 & $40.5 \pm 3.4$ & 27 & $40.7 \pm 3.4$ & 3 & $38.7 \pm 3.4$ & 0.351 \\
\hline $18.5 \leq \mathrm{BM}<24$ & 340 & $51.4 \pm 5.0$ & 250 & $51.0 \pm 5.0$ & 90 & $52.4 \pm 4.8$ & $0.022^{*}$ \\
\hline $24 \leq \mathrm{BMI}<27$ & 233 & $58.8 \pm 4.5$ & 123 & $58.5 \pm 4.5$ & 110 & $60.1 \pm 4.4$ & 0.145 \\
\hline $27 \leq \mathrm{BMI}$ & 144 & $67.6 \pm 7.3$ & 54 & $67.3 \pm 7.0$ & 90 & $67.8 \pm 7.5$ & 0.684 \\
\hline
\end{tabular}

Note: Student's $t$ test were used, compare with with-Mets and without-MetS group. ${ }^{*}$ means $p<0.05$, ${ }^{\dagger}$ means $p<0.01$. 
Table 4. Odds ratios of metabolic syndrome in different gender according to BMI groups.

\begin{tabular}{|c|c|c|c|c|c|c|}
\hline \multirow{2}{*}{ Variable } & \multicolumn{3}{|c|}{$\operatorname{Men}(n=433,36.7 \%)$} & \multicolumn{3}{|c|}{ Women $(\mathrm{n}=747,63.3 \%)$} \\
\hline & OR & $95 \% \mathrm{CI}$ & $P$ value & OR & $95 \% \mathrm{CI}$ & $P$ value \\
\hline Total & 1.11 & $1.08-1.14$ & $<0.001^{\dagger}$ & 1.08 & $1.06-1.10$ & $<0.001^{\dagger}$ \\
\hline \multicolumn{7}{|l|}{ BMI groups $\left(\mathrm{kg} / \mathrm{m}^{2}\right)$} \\
\hline $\mathrm{BMI}<18.5$ & - & - & - & 0.85 & $0.60-1.20$ & 0.352 \\
\hline $18.5 \leq \mathrm{BM}<24$ & 1.11 & $1.01-1.21$ & $0.021^{*}$ & 1.06 & $1.01-1.11$ & $0.023^{*}$ \\
\hline $24 \leq \mathrm{BMI}<27$ & 1.09 & $1.02-1.17$ & $0.013^{*}$ & 1.05 & $0.99-1.11$ & 0.142 \\
\hline $27 \leq \mathrm{BMI}$ & 1.01 & $0.95-1.08$ & 0.712 & 1.01 & $0.96-1.06$ & 0.686 \\
\hline
\end{tabular}

Note: Multiple logistic regression analysis, adjusted for age, smoking status, alcohol consumption, exercise status, living condition, and educational level. ${ }^{*}$ means $p<0.05$, 'means $p<0.01$.

pay more attention to their health than others. However, we controlled other confounding factors such as age, smoking status, alcohol consumption, exercise status, living condition, and educational level. We found that the odds ratios for an addition of $1 \mathrm{~kg}$ were 1.11 and 1.06 in men and women, respectively, in the BMI 18.5 - 24.0 $\mathrm{kg} / \mathrm{m}^{2}$ group $(P=0.02)$ and 1.09 in men in the BMI 24.0 $-27.0 \mathrm{~kg} / \mathrm{m}^{2}$ group $(P=0.01)$.

In conclusion, individuals in the upper normal-weight and slightly overweight BMI groups showed a relatively high prevalence and were at an increased risk of developing metabolic syndrome and its components. The results showed the same trends as in the studies by StOnge and Tsai [9-11]. Moreover, metabolic syndrome exists even in individuals with normal weight and overweight (non-obese). Therefore, physicians should screen metabolic syndrome not only in obese but also in nonobese individuals to prevent type 2 diabetes and cardiovascular diseases

\section{REFERENCES}

[1] Department of Health (2011) The Executive Yuan. Statistics Report, Taiwan.

[2] Haffner, S.M., Valdez, R.A., Hazuda, H.P., Mitchell, B.D., Morales, P.A. and Stern, M.P. (1992) Prospective analysis of the nsulin-resistance syndrome (syndrome X). Diabetes, 41, 715-722. doi:10.2337/diabetes.41.6.715

[3] Isomaa, B., Almgren, P., Tuomi, T., Forsén, B., Lahti, K., Nissén, M., et al. (2001) Cardiovascular morbidity and mortality associated with the metabolic syndrome. Diabetes Care, 24, 683-689. doi:10.2337/diacare.24.4.683

[4] Trevisan, M., Liu, J., Bahsas, F.B. and Menotti, A. (1998) Syndrome $\mathrm{X}$ and mortality: A population-based study. Risk factor and life expectancy research group. American Journal of Epidemiology, 148, 958-966. doi:10.1093/oxfordjournals.aje.a009572

[5] Huang, K.C., Lee, M.S., Lee, S.D., et al. (2005) Obesity in the elderly and its relationship with cardiovascular risk factors in Taiwan. Obesity Research, 13,170-178.

doi:10.1038/oby.2005.22

[6] Tsai, H.J. and Tsai, A.C. (2012) Prevalence of metabolic syndrome in elderly taiwanese: Results from the nutrition and health survey in Taiwan (1999-2000).

http://apha.confex.com/apha/135am/techprogram/paper_1 50632.htm.

[7] Yao, C.A., Lee, L.T., Chen, C.Y. and Huang, K.C. (2005) The study of metabolic syndrome in elderly receiving health check-up. Taiwan Geriatrics \& Gerontology, 1, 1825.

[8] Ruderman, N.B., Schneider, S.H. and Berchtold, P. (1981) The "metabolically-obese", normal-weight individual. American Journal of Clinical Nutrition, 34, 1617-1621.

[9] St-Onge, M.P., Janssen, I. and Heymsfield, S.B. (2004) Metabolic syndrome in normal-weight Americans: New definition of the metabolically obese, normal-weight individual. Diabetes Care, 27, 2222-2228.

[10] Wildman, R.P., Muntner, P., Reynolds, K., McGinn., A.P, Rajpathak, S. and Wylie-Rosett, J., et al. (2008) The obese without cardiometabolic risk factor clustering and the normal weight with cardiometabolic risk factor clustering: Prevalence and correlates of 2 phenotypes among the US population (NHANES 1999-2004). Archives International Medicine, 168, 1617-1624.

doi:10.1001/archinte.168.15.1617

[11] Tsai, C.H. (2009) Metabolic syndrome in non-obese Taiwanese: New definition of metabolically obese, normalweight individual. Chinese Medical Journal, 122, 2534 2539.

[12] Bureau of Health Promotion Database (2012) The criteria of metabolic syndrome.

http://www.bhp.doh.gov.tw/BHPnet/Portal/Them Show.a spx? Subject $=201109290001 \&$ Class $=2 \& \mathrm{No}^{2}=2011110100$ 04.

[13] Department of Health (2003) Identification, evaluation, and treatment of overweight and obesity in adults in Taiwan. Department of Health, Taiwan.

[14] Department of Health, Executive Yuan (2002) The Public health impact of obesity.

http://www.doh.gov.tw/NewVersion/content 
[15] Hwang, L.C., Bai, C.H. and Chen, C.J. (2006) Prevalence of obesity and metabolic syndrome in Taiwan. Journal of Formosa Medicine Association, 105, 626-635.

[16] Bureau of Health Promotion, Department of Health (2012) The method of measuring waist circumference of adult.
http://www.bhp.doh.gov.tw/bhpnet/portal/Them Show.as px? Subject $=200712250011 \&$ Class $=2 \& N_{0}=20071225014$ $\underline{4}$

[17] Schurgin, S. and Siegel, R.D. (2003) Pharmacotherapy of obesity: An update. Nutrion Clinical Care, 6, 27-37. 